\title{
An attempt to control Cameraria ohridella using an attract-and-kill technique
}

\author{
Lidia Sukovata • Darek Czokajlo • Andrzej Kolk • \\ Sławomir Ślusarski · Tomasz Jabłoński
}

Received: 1 March 2010/Accepted: 8 November 2010/Published online: 26 November 2010

(C) The Author(s) 2010. This article is published with open access at Springerlink.com

\begin{abstract}
This study estimates the efficacy of an attractand-kill (A\&K) technique to control the horse chestnut leaf miner, Cameraria ohridella Deschka and Dimic (Lepidoptera, Gracillariidae), an invasive insect pest of the horse chestnut, Aesculus hippocastanum L. (Hippocastanaceae). The A\&K formulation was dispensed as $50 \mu \mathrm{l}$ droplets of paste-like matrix, containing $C$. ohridella sex pheromone, (8E,10Z)-tetradeca-8,10-dienal $(85 \%+$ pure; $0.16 \% \mathrm{w} / \mathrm{w})$ and a fast acting contact toxicant, pyrocides (94\% pure; $6 \%$ $\mathrm{w} / \mathrm{w}$ ), applied directly to the bark of the trees. It was tested in 2003 at rates of 30 and 45 droplets/tree at the Ostrobramska site and at rates of 30, 60 and 90 droplets/tree at the Woloska site in Warsaw, Poland, for the first insect generation. A set of untreated plots ( 0 droplets/tree) was established at each site as well. The treatment efficacy was estimated using two indices: (1) moth catches in pheromone traps and (2) the number of mines per leaf. Trap catches were significantly higher in the untreated plots than in the treated plots regardless of the application rate in all sites. However, there were no significant differences in leaf damage amongst all plots on each site. At the "Lazienki Krolewskie" park the attractiveness of two types of pheromone sources were compared: traps were baited with rubber septum lures or with A\&K droplets. The catches of $C$. ohridella in traps baited with lures were lower than captures in A\&K droplet-baited
\end{abstract}

Communicated by A. Battisti

L. Sukovata $(\bowtie) \cdot$ A. Kolk · S. Ślusarski · T. Jabłoński Forest Protection Department, Forest Research Institute, 3, Braci Leśnej St, Sękocin Stary, 05-090 Raszyn, Poland e-mail: L.Soukovata@ibles.waw.pl

D. Czokajlo

Alpha Scents, Inc., 2070 Tumwater St, West Linn, OR 97068, USA traps, but the difference was not significant. Possible reasons for the low efficacy of the A\&K method in management of C. ohridella and reducing leaf damage are discussed.

Keywords Cameraria ohridella $\cdot$ Horse chestnut leafminer · Attract-and-kill · Aesculus hippocastanum

\section{Introduction}

The horse chestnut leaf miner, Cameraria ohridella, is a new invasive pest of the horse chestnut, Aesculus hippocastanum in Europe. The origin of this insect is not known. It was first observed in Macedonia in 1984 (Deschka and Dimic 1986), and has spread over large areas of Europe. In Poland it appeared in 1998 and infested horse chestnut trees throughout the country within a few years. With usually three generations per year, a population can reach high densities within 2 to 3 years from establishment on new sites. As a result of feeding activity of the mining larvae, leaves of horse chestnut trees wither and drop in early summer. High infestations cause a second flowering that results in fewer fruits and seeds per fruit than expected; however, it appears there is no direct risk of tree die-back (Heitland 2006; Nardini et al. 2004; Raimondo et al. 2003).

Rapid spread and population increase of C. ohridella is favored by a low effectiveness of natural enemies (Grabenweger 2004; Grabenweger et al. 2005a, b). Many research groups have been working to develop methods of C. ohridella management (Freise and Heitland 2003; Kehrli et al. 2005; Lehmann 2003). The most effective methods so far are based on leaf litter removal (Gilbert et al. 2003; Grabenweger 2001; Kehrli and Bacher 2003; Pavan et al. 2003) and chemical control by spraying horse chestnut trees with chemical insecticides (Šefrová 2001) or 
the application of systemic insecticides (Gargani et al. 2002; Lohrer et al. 2003).

In 1999 Svatoš et al. (1999) identified the pheromone of C. ohridella as (8E,10Z)-tetradeca-8,10-dienal (hereinafter 8E10Z-14:Ald). Later Hoskovec et al. (2000) described its synthesis and Francke et al. (2002) conducted the studies that confirmed pheromone structure, synthesis and biological activity. Since that time various semiochemical-based control techniques such as mass trapping, including female mass trapping, mating disruption and autoconfusion have been tested (Harand and Schmolling 2006; Kindl et al. 2004; Siekmann et al. 2006b; Svatoš et al. 2009; Wolfgang et al. 2004) using the $C$. ohridella pheromone or kairomone. Their efficacy appeared to be rather low in highdensity populations and thus may only be appropriate as a part of an integrated pest management system.

An attract-and-kill (A\&K) technology is a novel approach for protecting A. hippocastanum against $C$. ohridella. It is intended to suppress the male moth population by attracting them with sex pheromone to an insecticidetreated gel formulation, thus killing them and consequently preventing mating. There were the only studies testing A\&K so far conducted by Siekmann et al. (2006a). The "Last Call HCLM" formulation applied at a very low dosage of 1-5 droplet/tree in semi-field conditions caused no effect on leaf damage by $C$. ohridella.

This article presents the results of the experiments aiming to estimate the efficacy of $A \& K$ formulation at much higher dosages (30-90 droplets per tree) against C. ohridella in urban conditions.

\section{Materials and methods}

\section{Experimental sites}

The studies were conducted on horse chestnut trees growing along the Ostrobramska and Woloska Streets in Warsaw, Poland (hereafter called the Ostrobramska and Woloska sites, respectively). Trees were 7-9-m tall at Ostrobramska site and 10-13-m tall at Woloska site. The experiment with traps containing lures or A\&K droplets was conducted in the "Lazienki Krolewskie" Park in Warsaw.

\section{Materials}

The attract-and-kill (A\&K) formulation consists of a pastelike matrix containing a $C$. ohridella sex pheromone, 8E10Z14:Ald (85\% + pure; $0.16 \%$ w/w; IPM Tech, Inc, Portland, OR, USA) and a fast acting contact toxicant, pyrocides (94\% pure; $6 \%$ w/w; Valent Biosciences, Libertyville, IL, USA). $93.84 \%$ of the A\&K formulation consisted of UV-stabilizers, antioxidants, stickers and thickeners. The A\&K formulation was dispensed as $50 \mu \mathrm{l}$ droplets directly to the bark of the trees.

Populations of $C$. ohridella were monitored using green delta traps (IPM Tech, Inc., Portland, OR, USA) baited with lures. Trap lures were grey rubber septa (West Pharmaceutical, Pittsburgh, Pennsylvania, USA) impregnated with $0.05 \mathrm{mg}$ of sex pheromone plus $3 \%$ of BHT.

Experiments with application rates

The experiment was set up at both Ostrobramska and Woloska sites on 30 April 2003, which is for the first generation of $C$. ohridella. A\&K droplets were applied uniformly, 20-30 cm apart, on stems and branches in the lower parts of 20-30-year old trees at a height of 1.7-4.0 m above the ground.

At the Ostrobramska site, the A\&K formulation was applied at the rates of 0 (untreated), 30, and 45 droplets/tree (three experimental units) in three replicates (plots) on 5-10 trees per plot on both sides of the street (the scheme is shown on Fig. 1). At the Woloska site, the treated trees were located along one side of the street, and the droplets were applied at $0,30,60$, and 90 droplets/tree (four experimental units) in three replicates (plots) with five trees per plot.

Treatment efficacy

Treatment efficacy was estimated using two methods:

(1) Trap catch: We used 45 sticky delta traps at the Ostrobramska site and 60 traps at the Woloska site (five traps per plot). The traps were installed on 30 April and checked on 12 and 20 May at the former site and on 13 and 20 May at the latter site. Each time the traps were checked, the sticky inserts were replaced with new ones. Trap saturation was not observed in any case.

(2) Leaf damage (number of mines per leaf): On 1 July, at the end of the flight period of the first insect generation, four leaves were sampled from five trees in four (E, W, N and S) directions (80 leaves per plot) at the Ostrobramska site. At the Woloska site, four leaves from three inner trees (48 leaves per plot) in each cardinal direction were sampled. Mines were counted in the laboratory, and mean numbers of mines per leaf were calculated.

Experiment with lures and A\&K droplets

On 12 May 2003, sticky delta traps baited with septa lures or A\&K droplets loaded with 0.05 and $0.08 \mathrm{mg}$ of sex pheromone, respectively, were installed in 8 replicates in 80 -year old horse chestnut trees along a road in the "Lazienki 
Fig. 1 Scheme of tree and treatment block location at the Ostrobramska site, Warsaw, 2003. Numbers designate application rates (droplets/tree) of the $A \& \mathrm{~K}$ formulation

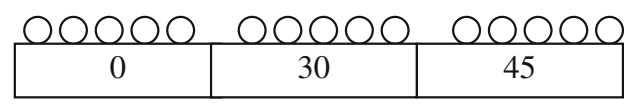

Ostrobramska Street

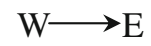

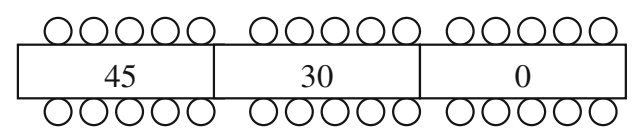

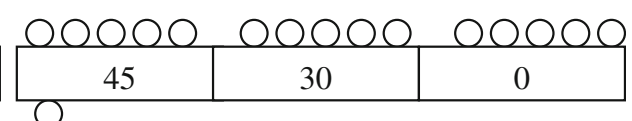

- treated tree

Krolewskie" park. Trees were about 20-m tall, and traps were hung 6-8 $\mathrm{m}$ above the ground (at the bottom of the crown). The traps were removed on 20 May and moths counted.

Data analysis

Counts of moths in the pheromone traps and numbers of mines/leaf in the A\&K experiments were analysed using one-way ANOVA $(\alpha=0.05)$ followed by Fisher's LSD test. Mean numbers of moths/trap and mean numbers of mines/leaf in each plot were used for analysis. Data were ln-transformed: $x^{\prime}=\ln x$ to correct for heterogeneity of variances. Catches of moths in traps with lures or A\&K droplets were compared using the $t$-test after transformation: $x^{\prime}=\left(\frac{x}{1000}\right)^{3}$. Statistical analyses were performed using Statistica 7.1 (StatSoft Inc. 2005).

\section{Results}

Trap catches in A\&K testing experiment

The mean numbers of $C$. ohridella moths caught in the untreated plots were 49.0 and 67.6 moths/trap at the
Ostrobramska and Woloska sites, respectively (Fig. 2). In the plots treated with different $\mathrm{A} \& \mathrm{~K}$ application rates mean numbers of moths varied between 4.5 and 6.1 moths/trap at the Ostrobramska site and between 6.7 and 9.9 moths/trap at the Wołoska site. ANOVA revealed a marginally significant difference between trap catches in the untreated and treated plots, regardless of the application dose, with lower catches in latter ones. However, there were no significant differences amongst the treated plots on each site.

\section{Leaf damage in $A \& K$ testing experiment}

There were no significant differences in mean numbers of mines per leaf amongst the plots at both Ostrobramska and Woloska sites. Leaf damage level at the Ostrobramska site was from $2.4 \pm 1.75$ (mean $\pm \mathrm{SD}$ ) to $2.7 \pm 1.19$ mines/ leaf, and it varied between $4.8 \pm 1.78$ and $6.8 \pm 4.67$ mines/leaf at the Woloska site.

\section{Attractiveness of lure and A\&K droplet}

The mean number of $C$. ohridella moths in traps baited with rubber septa lures (1277.4 moths/trap) was lower but not significantly different $(t=2.00 d f=14 P=0.0650)$

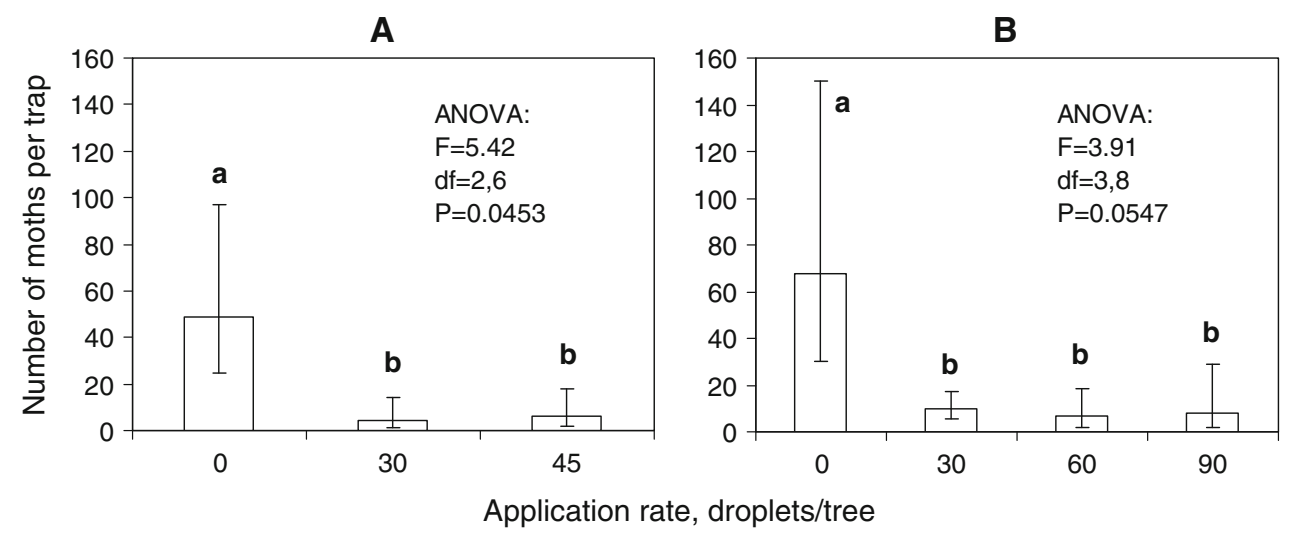

Fig. 2 Mean number of Cameraria ohridella male moths caught in the delta traps in the untreated plots and plots treated with the attractand-kill formulation at different application rates at the Ostrobramska (a) and Woloska (b) sites (30 April-20 May 2003). Moth counts with the same letter above are not significantly different $(\alpha=0.05$, ANOVA on ln-transformed data, vertical bars indicate \pm SD) 
than the mean number of moths in traps baited with A\&K droplets (1459.3 moths/trap).

\section{Discussion}

In this article, we demonstrate the use of the A\&K technique in an urban environment for management of $C$. ohridella. Trap catches indicate that male populations were either reduced or that males had difficulties in finding pheromone traps in treated areas. A\&K application caused trap shut down, but the leaf damage level was not reduced.

There are several possible reasons for the low efficacy of A\&K method in the management of $C$. ohridella and further reduction of leaf damage. One of the factors affecting efficacy of A\&K technology is the ability of a moth to find and contact a single droplet. It depends on pheromone load in the formulation and droplet density. The pheromone release rate from trap lures should generally be much higher than cumulative release rate of several females for 30 days. In contrast, pheromone content in an A\&K droplet should be slightly higher than monthly pheromone production by a single female. The trap catch data in our experiments suggest that pheromone load in the tested experimental A\&K formulation was too high. This may cause disruption of male response to the pheromone source at close range. Therefore, males may not have contacted the droplet and been killed, thus the observed reductions in trap captures may have resulted from a mating disruption effect of the treatment.

The ability of male moths to find and contact a single A\&K droplet depends also on the formulation point source density. It is supposed to be most effective, when the droplet density is low and plums of pheromone are discrete. Usually, A\&K gel is applied in orchards or plantations at rates from a few hundred to a few thousand droplets per ha (Charmillot and Hofer 1997; Hofer and Brassel 1992; Ioriatti and Angeli 2002; Sukovata et al. 2004; Weihman and Liburd 2006). However, some studies revealed no difference between formulations with and without insecticides at either low or high droplet density (Curkovic and Brunner 2007; Evenden and McLaughlin 2004; Sukovata et al. 2004), suggesting that the mechanism of A\&K action is by disruption of male moth orientation, and not by removal of males due to insecticide poisoning. Evenden and McLaughlin (2004) showed that the effectiveness of an attracticide would depend on the competition provided by natural sources of pheromones. When placed in traps in field cages, attracticide droplets were competitive with calling females of Grapholita molesta at ratios of 1:2 and $1: 4$, whilst at the ratio $1: 8$ there was a significant reduction in the proportion of males caught in the A\&K dropletbaited traps. In our study, the attracticide was applied at very high rate of 30-90 droplets per tree assuming that the density of droplets should be higher for dense pest populations. The lack of significant differences in leaf damage between untreated and $A \& K$ treated plots could be due to still too low droplet density. With thousands of $C$. ohridella moths per tree, the 30-90 droplets per tree would translate to $1: 10$ and higher ratios of droplets to calling females. Besides, in high-density populations, males may be able to find females by short-range search using visual or other stimuli (Curkovic et al. 2006; Daterman 1972).

Other reasons for the low efficacy of $A \& K$ formulation could be similar to those of mating disruption defined by Casagrande and Jones (1997): (1) the target insect is mobile and capable of dispersing locally over significant distances or is migratory; (2) the areas treated are too small or poorly isolated from surrounding crops with populations of the target insect. In our studies, the treated and untreated plots were very small and not isolated from each other; thus, migration of moths was possible and gravid females may have flown in from outside of the treated areas to lay eggs. The problem of insect migration from untreated to treated plots was also discussed by other researchers (Ioriatti and Angeli 2002; Mazomenos et al. 2002). This probably could be overcome by increasing treatment area to cover the whole area of insect occurrence and/or by a preceding decrease of population density (by insecticide treatment) to a level appropriate for pheromone application.

Some investigators suggest that height of trap location has a significant effect on captures (Sarzynski and Liburd 2004; Thwaite and Madsen 1983) and consequently the height of the A\&K droplet application could also affect treatment efficacy (Evenden and McLaughlin 2004). In our studies, trees were 7-13-m tall and were treated only up to a height of $4 \mathrm{~m}$, including lower tree branches. Since the C. ohridella moths of the first generation emerge from the litter as an overwintering place, mate on the tree stem below a crown, and lay eggs in the lower part of crowns (personal observations), it was assumed that placement of A\&K droplets on tree stems up to the lower part of a crown should be sufficient.

In the future, efficacy of A\&K gel with lower pheromone concentrations and applied at different densities of droplets per tree, treating the entire tree crown and trunk, should be evaluated. The density of droplets should be high enough to outcompete calling females, but still low enough not to cause a camouflage. Also, experimental plots should cover trees on entire city blocks that are well isolated from other Cameraria infestations and not small groups of trees in the same row.

Acknowledgments We would like to thank John McLaughlin for helpful comments on the manuscript. 
Open Access This article is distributed under the terms of the Creative Commons Attribution Noncommercial License which permits any noncommercial use, distribution, and reproduction in any medium, provided the original author(s) and source are credited.

\section{References}

Casagrande E, Jones OT (1997) Commercial exploitation of mating disruption technology: difficulties encountered and keys to success. IOBC/WPRS Bull 20(1):11-17

Charmillot PJ, Hofer D (1997) Control of codling moth, Cydia pomonella L., by an attract and kill formulation. Technology transfer in mating disruption. IOBC/WPRS Bull 20(1):139-140

Curkovic T, Brunner JF (2007) Choristoneura rosaceana (Harris) and Pandemis pyrusana Kearfott (Lepidoptera: Tortricidae) male control in Washington State (USA) apple orchards treated with different source densities of several attracticide formulations. Agric Tec 67:23-28

Curkovic T, Brunner JF, Landolt PJ (2006) Courtship behavior in Choristoneura rosaceana and Pandemis pyrusana (Lepidoptera: Tortricidae). Ann Entomol Soc Am 99:617-624. doi:10.1603/ 0013-8746(2006)99[617:CBICRA]2.0.CO;2

Daterman GE (1972) Laboratory bioassay for sex pheromone of the European pine shoot moth, Rhyacionia buoliana. Ann Entomol Soc Am 65:119-123

Deschka G, Dimic N (1986) Cameraria ohridella sp. n. (Lepidoptera, Lithocolletidae) aus Mazedonien, Jugoslawien. Acta Entomol Jugosl 22:11-23

Evenden ML, McLaughlin JR (2004) Factors influencing the effectiveness of an attracticide formulation against the Oriental fruit moth, Grapholita molesta. Entomol Exp Appl 112:89-97. doi: 10.1111/j.0013-8703.2004.00181.x

Francke W, Franke S, Bergmann J, Tolasch T, Subchev M, Mircheva A, Toshova T, Svatoš A, Kalinová B, Kárpáti Z, Szöcs G, Tóth M (2002) Female sex pheromone of Cameraria ohridella Desch. and Dim. (Lepidoptera: Gracillariidae): structure confirmation, synthesis and biological activity of (8E,10Z)-8,10-tetradecadienal and some analogues. Z Naturforsch 57c:739-752

Freise JF, Heitland W (2003) The Waipuna hot foam system-a chance for Cameraria ohridella control? Nachr Dtsch Pflanzenschutzd 55:242-244

Gargani E, Russo R, Del Bene G (2002) Control tests of the horsechestnut leafminer using methods with low environmental impact. Redia 85:131-141

Gilbert M, Svatoš A, Lehmann M, Bacher S (2003) Spatial patterns and infestation processes in the horse chestnut leafminer Cameraria ohridella: a tale of two cities. Entomol Exp Appl 107:25-37. doi:10.1046/j.1570-7458.2003.00038.x

Grabenweger G (2001) Auswirkungen der Fallaubentfernung auf Cameraria ohridella Deschka \& Dimic (Lepidoptera, Gracillariidae) und ihre Parasitoiden. Mitt Dtsch Ges Allg Angew Entomol 13:141-143

Grabenweger G (2004) Poor control of the horse chestnut leafminer, Cameraria ohridella (Lepidoptera: Gracillariidae), by native European parasitoids: a synchronisation problem. Eur J Entomol 101:189-192

Grabenweger G, Avtzis N, Girardoz S, Hrasovec B, Tomov R, Kenis M (2005a) Parasitism of Cameraria ohridella (Lepidoptera, Gracillariidae) in natural and artificial horse-chestnut stands in the Balkans. Agric For Entomol 7:291-296. doi:10.1111/ j.1461-9555.2005.00269.x

Grabenweger G, Kehrli P, Schlick-Steiner B, Steiner F, Stolz M, Bacher S (2005b) Predator complex of the horse chestnut leafminer Cameraria ohridella: identification and impact assessment. J Appl Entomol 129:353-362. doi:10.1111/j.1439-0418. 2005.00973.x

Harand W, Schmolling S (2006) Weibchen-Massenfang mit Kairomonen. Signifikante Populationsreduktion in Berlin und Wien mit Calantis-Kastanienminiermottenfallen. Nachr Dtsch Pflanzenschutzd 58:258-259

Heitland W (2006) Controcam-control of Cameraria. Nachr Dtsch Pflanzenschutzd 58:251-252

Hofer D, Brassel J (1992) "Attract and Kill" to control Cydia pomonella and Pectinophora gossypiella. IOBC/WPRS Bull 15(5):36-39

Hoskovec M, Šaman D, Svatoš A (2000) Synthesis of (8E,10Z)tetradeca-8,10-dienal, sex pheromone of horse chestnut leafminer (Cameraria ohridella), and all its geometrical isomers. Collect Czech Chem Commun 65:511-523

Ioriatti C, Angeli G (2002) Control of codling moth by attract and kill. IOBC/WPRS Bull 25(9):129-136

Kehrli P, Bacher S (2003) Date of leaf litter removal to prevent emergence of Cameraria ohridella in the following spring. Entomol Exp Appl 107:159-162. doi:10.1046/j.1570-7458.2003. 00043.x

Kehrli P, Lehmann M, Bacher S (2005) Mass-emergence devices: a biocontrol technique for conservation and augmentation of parasitoids. Biol Control 32:191-199

Kindl J, Hovorka O, Holý I, Kalinová B, Svatoš A (2004) Mating disruption and mass trapping-possible tools in Cameraria ohridella control? Abstracts, 1st International Cameraria Symposium, IOCB Prague, 24-27 March 2004, p 20

Lehmann M (2003) Bekämpfung der Kastanienminiermotte mit NeemAzal-T/S. Nachr Dtsch Pflanzenschutzd 55:237-239

Lohrer T, Gerlach WWP, Fischer P, Fuchsbichler G, Eichinger HM (2003) Untersuchungen zur Laub- und Kompostbelastung nach einer Bodenapplikation mit Imidacloprid zur Bekämpfung der Kastanienminiermotte Cameraria ohridella (Lepidoptera, Gracillariidae). Nachr Dtsch Pflanzenschutzd 55:240-241

Mazomenos BE, Pantazi-Mazomenou A, Stefanou D (2002) Attract and kill of the olive fruit fly Bactrocera oleae in Greece as a part of an integrated control system. IOBC/WPRS Bull 25(9): 137-146

Nardini A, Raimondo F, Scimone M, Salleo S (2004) Impact of the leaf miner Cameraria ohridella on whole-plant photosynthetic productivity of Aesculus hippocastanum: insights from a model. Trees 18:714-721. doi:10.1007/s00468-004-0358-3

Pavan F, Barro P, Bernardinelli I, Gambon N, Zandigiacomo P (2003) Cultural control of Cameraria ohridella on horsechestnut in urban areas by removing fallen leaves in autumn. J Arboric 29:253-258

Raimondo F, Ghirardelli LA, Nardini A, Salleo S (2003) Impact of the leaf miner Cameraria ohridella on photosynthesis, water relations and hydraulics of Aesculus hippocastanum leaves. Trees 17:376-382. doi:10.1007/s00468-003-0248-0

Sarzynski EM, Liburd OE (2004) Effect of trap height and withinplanting location on captures of cranberry fruitworm (Lepidoptera: Pyralidae) in highbush blueberries. Agric For Entomol 6:199-204. doi:10.1111/j.1461-9555.2004.00222.x

Šefrová H (2001) Control possibility and additional information on the horse-chestnut leafminer Cameraria ohridella Deschka \& Dimic (Lepidoptera, Gracillariidae). Acta Univ Agric Silvic Mendel Brun 49:121-127

Siekmann G, Meyhöfer R, Hommes M (2006a) Untersuchungen zur Wirksamkeit des Produkts "Last Call HCLM" für eine Attract \& Kill Bekämpfungsstrategie. Nachr Dtsch Pflanzenschutzd 58:253

Siekmann G, Meyhöfer R, Kalinova B, Hommes M (2006b) Versuchsreihe zur Pheromon-Verwirrungstechnik gestartet: Viel 
Pheromon und wenig Verwirrung? Nachr Dtsch Pflanzenschutzd $58: 254$

StatSoft Inc (2005) STATISTICA (data analysis software system), version 7.1. www.statsoft.com

Sukovata L, Kolk A, Cieślak M (2004) Effect of attract and kill formulations and application rates on trap catches of European pine shoot moth (Lepidoptera: Tortricidae) and shoot damage in Scots pine saplings. J Econ Entomol 97:1619-1623. doi: 10.1603/0022-0493-97.5.1619

Svatoš A, Kalinová B, Hoskovec M, Kindl J, Hovorka O, Hrdý I (1999) Identification of a new lepidopteran sex pheromone in picogram quantities using an antennal biodetector: (8E,10Z)tetradeca-8,10-dienal from Cameraria ohridella. Tetrahedron Lett 40:7011-7014

Svatoš A, Kalinová B, Hrdý I (2009) Cameraria ohridella: 10 years of sex pheromone and kairomone research. J Appl Entomol 133:319-327. doi:10.1111/j.1439-0418.2008.01355.x
Thwaite WG, Madsen HF (1983) The influence of trap density, trap height outside traps and trap design on Cydia pomonella (L.) captures with sex pheromone traps in New South Wales apple orchards. Aust J Entomol 22:97-99. doi:10.1111/j.1440-6055. 1983.tb01850.x

Weihman SW, Liburd OE (2006) Mating disruption and attract-andkill as reduced-risk strategies for control of grape root borer Vitacea polistiformis (Lepidoptera: Sesiidae) in Florida vineyards. Fla Entomol 89:245-250. doi:10.1653/0015-4040(2006) 89[245:MDAAAR]2.0.CO;2

Wolfgang H, Stolz M, Hadacek F (2004) Female mass trapping-a contribution to Cameraria ohridella control. Abstracts, 1st International Cameraria Symposium, IOCB Prague, 24-27 March 2004, p 13 